\title{
Suppression of $\mathrm{T}_{\mathrm{H}} 17$ Differentiation and Autoimmunity by a Synthetic ROR Ligand
}

\author{
Laura A. Solt ${ }^{1}$, Naresh Kumar ${ }^{1,2}$, Philippe Nuhant ${ }^{4}$, Yongjun Wang ${ }^{1}$, Janelle L. Lauer ${ }^{1}$, Jin \\ Liu $^{1}$, Monica A. Istrate ${ }^{1,2}$, Theodore M. Kamenecka ${ }^{3}$, William R. Roush ${ }^{4}$, Dušica Vidović 2,5 , \\ Stephan C. Schürer ${ }^{2,5}$, Jihong $\mathbf{X u}^{6}$, Gail Wagoner ${ }^{6}$, Paul D. Drew ${ }^{6}$, Patrick R. Griffin ${ }^{1,2,3}$, \\ and Thomas P. Burris ${ }^{1}$ \\ ${ }^{1}$ Department of Molecular Therapeutics, The Scripps Research Institute, Jupiter, Florida 33458 \\ ${ }^{2}$ The Scripps Research Institute Molecular Screening Center, The Scripps Research Institute, \\ Jupiter, Florida 33458 \\ ${ }^{3}$ The Translational Research Institute, The Scripps Research Institute, Jupiter, Florida 33458 \\ ${ }^{4}$ Department of Chemistry, The Scripps Research Institute, Jupiter, Florida 33458 \\ ${ }^{5}$ Center for Computational Science University of Miami, Miami, FL 33136 \\ ${ }^{6}$ Department of Neurobiology and Developmental Sciences, University of Arkansas for Medical \\ Sciences, Little Rock, AR, 72205
}

\begin{abstract}
$\mathrm{T}$ helper cells that produce Interleukin-17 (IL-17) $\left(\mathrm{T}_{\mathrm{H}} 17\right.$ cells) are a recently identified $\mathrm{CD}^{+}{ }^{+} \mathrm{T}-$ cell subset with characterized pathological roles in autoimmune diseases ${ }^{1-3}$. The nuclear receptors retinoic acid receptor-related orphan receptors $\alpha$ and $\gamma \mathrm{t}(\mathrm{ROR} a$ and $\mathrm{ROR} \gamma \mathrm{t}$ ) have indispensible roles in the development of this cell type ${ }^{4-7}$. Here we present a first-in-class, high-affinity synthetic ligand, SR1001, specific to both RORa and ROR $\gamma$ t that inhibits $\mathrm{T}_{\mathrm{H}} 17$ cell differentiation and function. SR1001 binds specifically to the ligand binding domains (LBDs) of RORa and ROR $\gamma$ t inducing a conformational change within the LBD that encompasses repositioning of helix 12 leading to diminished affinity for coactivators and increased affinity for corepressors resulting in suppression of the receptors transcriptional activity. SR1001 inhibited the development of murine $\mathrm{T}_{\mathrm{H}} 17$ cells as demonstrated by inhibition of IL-17A gene expression and protein production. Additionally, SR1001 inhibited the expression of cytokines when added to differentiated murine or human $\mathrm{T}_{\mathrm{H}} 17$ cells. Finally, SR1001 effectively suppressed the clinical severity of autoimmune disease in mice. Thus, our data demonstrates the feasibility of targeting the orphan receptors $\mathrm{RORa}$ and $\mathrm{ROR} \gamma \mathrm{t}$ to specifically inhibit $\mathrm{T}_{\mathrm{H}} 17$ cell differentiation and
\end{abstract}

\footnotetext{
Users may view, print, copy, download and text and data- mine the content in such documents, for the purposes of academic research, subject always to the full Conditions of use: http://www.nature.com/authors/editorial_policies/license.html\#terms

Corresponding author Correspondence to: Thomas Burris (tburris@ scripps.edu).

Author Contributions P.R.G and T.P.B. conceived the project. L.A.S., P.R.G., and T.P.B. planned the project. Medicinal chemistry was planned and performed by P.N., T.M.K. and W.R.R. Biochemical and cell based assays were performed by L.A.S., N.S., Y.W., J.L., and M.A.I. Molecular modeling was performed by D.V and S.C.C. The EAE model was designed and performed by J.X., G.W. and P.D.D. HDX studies were performed by J.L.L. The manuscript was written by L.A.S. and T.P.B.

Competing Financial Interests The authors declare no competing financial interests.
} 
function and indicates that this novel class of compound has potential utility in the treatment of autoimmune diseases.

$\mathrm{T}_{\mathrm{H}} 17$ cells are crucial effector cells implicated in the pathology of numerous autoimmune diseases, including multiple sclerosis, rheumatoid arthritis, inflammatory bowel disease, and systemic lupus erythematosis. These cells produce a number of cytokines, including IL-17, which are known to enhance inflammatory processes ${ }^{1-3}$. The discovery of these cells as critical mediators of autoimmune disorders provides a unique opportunity to develop focused therapeutics that act by inhibiting the function of these cells. An essential role for two nuclear receptors (NRs), RORa and ROR $\gamma$ t, has been established in the development of $\mathrm{T}_{\mathrm{H}} 17$ cells. Both of these NRs are required for the full differentiation of naïve $\mathrm{CD} 4^{+} \mathrm{T}$ cells into $\mathrm{T}_{\mathrm{H}} 17$ cells $^{4-7}$.

Members of the NR superfamily are ligand-dependent transcription factors. A number of drugs utilized in the clinic have been developed that target several NR superfamily members. Therefore, an attractive strategy for the development of novel therapeutics for treatment of $\mathrm{T}_{\mathrm{H}} 17$-mediated autoimmune disorders is targeting RORa and ROR $\gamma \mathrm{t}$ with synthetic ligands that inhibit their activity resulting in decreased $\mathrm{T}_{\mathrm{H}} 17$ cell differentiation and/or function. However, RORs are generally characterized as orphan receptors with no well-characterized ligands, thus it is unclear whether this approach is viable.

We recently characterized the benzenesulfonamide liver X receptor (LXR) agonist T0901317 (T1317) as a promiscuous ligand that modulates the activity of several NRs including RORa and ROR $\gamma^{8}$. While T1317 is a very potent and efficacious agonist of LXR, it also acts as an inverse agonist of RORa and ROR $\gamma$ by suppressing their basal transcriptional activity ${ }^{8}$. Using the T1317 scaffold as a lead compound we developed a derivative, SR1001 (Fig. 1a and Supplementary Fig. 1) that was devoid of all LXR activity yet retained its ability to suppress the activity of RORa and ROR $\gamma$. We found that SR1001 repressed both GAL4-RORa and GAL4-ROR $\gamma$ transcriptional activity in a dose dependent manner (Fig. 1b), but demonstrated no effect on LXRa activity (Fig. 1b). We assessed the specificity of SR1001 in a panel of all 48 human nuclear receptors in a cell-based cotransfection assay ${ }^{8}$ and did not observe activity on receptors other than RORa or ROR $\gamma$ (data not shown). We examined the direct binding of SR1001 to RORa and ROR $\gamma$ using competitive radioligand binding assays. SR1001 dose dependently displaced $\left[{ }^{3} \mathrm{H}\right] 25-$ hydroxycholesterol binding to RORa and $\operatorname{ROR} \gamma\left(\mathrm{K}_{\mathrm{i}}=172\right.$ and $111 \mathrm{nM}$, respectively) (Fig. 1c) but demonstrated no binding to ROR $\beta$ (data not shown).

We examined whether SR1001 would affect RORa- and ROR $\gamma$-dependent regulation of an $1 l 17$ promoter-driven luciferase reporter ${ }^{9}$. HEK293 cells were transfected with the $I l 17$ reporter and either full-length RORa or ROR $\gamma$ and treated with SR1001 or vehicle. As illustrated in Fig. 1d, SR1001 dose-dependently suppressed the $I l 17$ promoter driven activity by each of the receptors. Since SR1001 bound RORa and ROR $\gamma$, resulting in suppression of each receptors' transcriptional activity, we expected that SR1001 would inhibit coactivator binding to the receptors. SR1001 reduced the interaction of a coactivator TRAP220 NR box 2 peptide with ROR $\gamma$ in a dose dependent manner (Fig. 1e) $\left(\mathrm{IC}_{50}\right.$ value $\sim 117 \mathrm{nM}$ ). 
Collectively, these data demonstrate that SR1001 function as an inverse agonist ligand of $\mathrm{RORa} / \mathrm{ROR} \gamma$.

Next, we determined whether SR1001 affected endogenous $1117 a$ gene expression. The EL4 murine tumor cell line constitutively expresses RORa (Rora), ROR $\gamma \mathrm{t}$ (Rorc), and IL-17A $(I l 17 a)^{10}$. EL4 cells were treated with either control siRNA or a mixture of RORa/ $\gamma$ siRNA followed by treatment with either vehicle or SR1001. Reduction in the expression of RORa and ROR $\gamma \mathrm{t}$ significantly reduced the expression of IL-17A mRNA as measured by quantitative PCR (Fig. 2a). More importantly, treatment of cells with SR1001 suppressed Ill7a mRNA expression whereas treatment of RORa $/ \gamma$ depleted cells displayed a significantly blunted response indicating that SR1001 suppression of $1117 a$ mRNA expression is RORa/ROR $\gamma$ dependent (Fig. 2a). Furthermore, SR1001 suppressed the expression of the RORa and ROR $\gamma$ target gene G6Pase in HepG2 cells, a human hepatocellular carcinoma cell line, providing further proof that the effect of SR1001 is mediated by RORa and ROR $\gamma$ (Supplementary Fig. 2) ${ }^{11,12}$.

We hypothesized that SR1001 would inhibit binding of the coactivator SRC2 to either RORa or ROR $\gamma$ when these receptors are occupying the Ill7 promoter. We performed a sequential chromatin immunoprecipitation assay (ChIP-reChIP) assessing the relative amount of SRC2 associated with either RORa or ROR $\gamma$ resident at the $I l 17$ promoter in EL4 cells. SR1001 suppressd the ability of SRC2 to bind to RORa and ROR $\gamma$ at the Ill7 promoter and increased the recruitment of the corepressor NCoR (Fig. 2b, lanes 3 and 4 and Fig. 2c, lanes 3 and 4). Thus, SR1001 suppresses $I l 17 a$ expression by directly inhibiting coactivator binding and promoting the recruitment of corepressors to RORa and ROR $\gamma$.

To understand how ligand mediates the transcriptional activation of ROR $\gamma$, we performed comprehensive differential hydrogen-deuterium exchange mass spectrometry (HDX) analysis of the ROR $\gamma$ LBD in the presence and absence of SR1001. This approach provides a measure of the localized ligand-induced perturbation in the conformational ensemble of the receptor. HDX kinetics of peptic peptides derived from the ROR $\gamma$ LBD were measured and the average difference in percentage of incorporated deuterium between apo ROR $\gamma$ LBD and SR1001 bound ROR $\gamma$ LBD are presented in Supplementary Figure 3. A negative value represents an increase in protection to exchange (more stable, less dynamic) in that region of the LBD when bound to ligand as compared to apo whereas a positive value represents a decrease in protection to exchange (less stable, more dynamic). HDX kinetics are sensitive to hydrogen bond networks and perturbations in these networks upon ligand binding can be determined using differential HDX. The differential HDX induced by SR1001 binding to ROR $\gamma$ correlates with the co-crystal structure of ROR $\gamma$ complexed with the sterol ligand, 25-hydroxycholesterol 25-OHC (PDB:3LOL) ${ }^{13}$ (Supplementary Fig. 4). In the ROR $\gamma / 25-\mathrm{OHC}$ structure, the $\mathrm{C} 25$ hydroxyl tail is oriented towards helix 11 (H11) and the A ring toward $\mathrm{H} 1 / \mathrm{H} 2$. As can be inferred from PDB:3LOL, the hydroxyl group at the $\mathrm{C} 1$ position of 25-OHC is hydrogen bonded to Qln-286 (H1) and the 25-hydroxyl is hydrogen bonded to His-479 (H11). The regions within the ROR $\gamma$ LBD that show increased protection to exchange upon binding of SR1001 include portions of H1 and H11. To highlight this, the HDX data in Supplementary Fig. 3 is represented graphically by overlay onto PDB:3LOL with SR1001 docked (Fig. 2d). Consistent with the differential HDX data, docking of 
SR1001 to PDB:3LOL suggests a similar binding mode for SR1001 to ROR $\gamma$ (Supplementary Fig. 4).

In order to examine the role of SR1001 in modulation of this interaction between SRC2 and ROR $\gamma$, we performed differential HDX on ROR $\gamma$ LBD in the presence and absence of the receptor interaction domain (RID) of SRC2 (Fig. 2d \& Supplementary Fig.3), which contains three NR boxes ( 18kDa). Several regions of the LBD demonstrate reduced HDX kinetics in the presence of SRC2 RID, indicating an interaction between the two proteins. One region stabilized is $\mathrm{H} 12$, containing the AF2 domain of the receptor, which has been shown to be important for NR interaction with coactivators. Furthermore, differential HDX analysis of the ROR $\gamma:$ SRC2 complex in the presence and absence of SR1001 clearly demonstrates that ligand disrupts the receptors interaction with SRC2 RID (Fig. 2d). These data provide strong mechanistic insight into how inverse agonists such as SR1001 repress transcriptional output of $\mathrm{ROR} \gamma$ target genes.

Since RORa and ROR $\gamma$ activity is required for optimal $\mathrm{T}_{\mathrm{H}} 17$ cell development ${ }^{4}$, we explored whether SR1001 would inhibit $\mathrm{T}_{\mathrm{H}} 17$ cell differentiation. Splenocytes were cultured under $\mathrm{T}_{\mathrm{H}} 17$ polarizing conditions (TGF- $\beta$ and IL-6) with SR1001 or vehicle control for 5 days. The combination of TGF- $\beta$ and IL-6 increased the mRNA expression of $1117 a$, $I l 17 f$, Il21, and $I l 22$, in vehicle treated cells whereas SR1001 treated cells failed to significantly upregulate these cytokines (Fig. 3). Propidium iodide staining indicated that SR1001 was not toxic and did not induce cell death (Supplementary Fig. 5). $\mathrm{T}_{\mathrm{H}} 17$ cells and inducible $\mathrm{T}$ regulatory cells $\left(\mathrm{iT}_{\text {reg }}\right.$ ) are both dependent on TGF $\beta$ for their differentiation. We

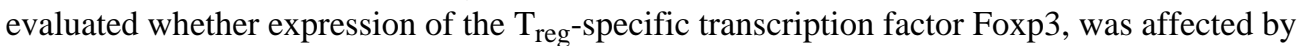
SR1001 treatment. Similar to vehicle control, Foxp3 mRNA expression was unaffected by SR1001 treatment suggesting that inhibition of $\mathrm{T}_{\mathrm{H}} 17$ cell differentiation by SR1001 did not drive the cells into an $\mathrm{iT}_{\text {reg }}$ phenotype (Supplementary Fig. 6) ${ }^{9}$. Furthermore, suppression of $\mathrm{T}_{\mathrm{H}} 17$ cell development with SR1001 treatment did not drive the splenocyte cultures into any of the other $\mathrm{T}$ helper lineages, $\mathrm{T}_{\mathrm{H}} 1$ or $\mathrm{T}_{\mathrm{H}} 2$, as indicated by the decrease in $T b x 21$ (T-bet) and Gata3 mRNA expression, respectively (Supplementary Fig. 6).

Finally, we explored whether SR1001 would inhibit IL-17 protein production and secretion. Splenocytes were cultured under $\mathrm{T}_{\mathrm{H}} 17$ polarizing conditions and analyzed for IL-17 expression by intracellular flow cytometry. Treatment with SR1001 inhibited the expression of IL-17 from CD4 ${ }^{+} \mathrm{T}$ cells at Day 4, 5, and 6 (Fig. 4a). Similar to splenocyte cultures, intracellular flow cytometry demonstrated that SR1001 significantly repressed IL-17 expression in purified differentiated murine $\mathrm{CD} 4^{+} \mathrm{T}$ cells $\left(\mathrm{CD} 4{ }^{+} \mathrm{CD} 25^{-} \mathrm{CD} 62 \mathrm{~L}^{\mathrm{hi}} \mathrm{CD} 44^{\mathrm{lo}}\right)$ (Fig. 4b). Next we assessed the effect of SR1001 on IL-17 secretion from splenocyte cultures by ELISA. Treatment with SR1001 inhibited IL-17 secretion over a three-day time course, when SR1001 was added at either the initiation of $\mathrm{T}_{\mathrm{H}} 17$ cell differentiation (initiation) or 48 hours post initiation of differentiation (post) (Fig. 4c). SR1001 was also effective at inhibiting intracellular IL-17 expression in human peripheral blood mononuclear cells (hPBMCs) (Fig. 4d). Finally, we examined the effects of SR1001 on other T helper cell lineages. Differentiation of $\mathrm{T}_{\mathrm{H}} 1, \mathrm{~T}_{\mathrm{H}} 2$, and iT ${ }^{\text {reg }}$ cells was unaffected by SR1001 treatment as similar amounts of IFN $\gamma$, IL-4, or Foxp3, respectively, were expressed compared to 
vehicle controls, indicating that SR1001 specifically targets $T_{H} 17$ cells (Supplementary Fig. $7)$.

Given that RORa and ROR $\gamma \mathrm{t}$ are required for development of $\mathrm{T}_{\mathrm{H}} 17$-mediated autoimmune diseases ${ }^{4,5}$ and SR1001 inhibits the activity of both of these receptors leading to suppressed $\mathrm{T}_{\mathrm{H}} 17$ cell development in vitro, we evaluated the effects of SR1001 treatment in an animal model of multiple sclerosis, experimental autoimmune encephalomyelitis (EAE), a well characterized model of $\mathrm{T}_{\mathrm{S}} 17$ cell-mediated autoimmune disease ${ }^{14,15}$. After myelin oligodendrocyte glycoprotein $\left(\mathrm{MOG}_{35-55}\right)$ immunization at day 0 , mice were treated with 25 $\mathrm{mg} \mathrm{kg}^{-1}$ of SR1001 b.i.d. i.p. for the duration of the study. As shown in Figure 4e, SR1001 treatment delayed the onset and clinical severity of EAE. Further analysis of spinal cords from mice harvested at day 18 post-immunization revealed that SR1001 repressed $1 l 17 a$ mRNA expression by $\sim 60 \%$, as well as reduced $I l 21$, and $I l 22$ mRNA expression (Fig. 4f). Intracellular cytokine analysis of splenocytes indicated a significant reduction in IL-17 expression and reduced total $\mathrm{CD} 4^{+} \mathrm{T}$ cells with no effect on $\mathrm{CD} 8^{+} \mathrm{T}$ cells. mRNA expression of IL-4 and IFN $\gamma$ was unaffected in both spleen and spinal cords (Supplementary Fig. 8). These data are consistent with our interpretation that SR1001 suppresses EAE through its effects on $\mathrm{T}_{\mathrm{H}} 17$ cell function in vivo. Further optimization of SR1001 may yield compounds with greater activity.

While RORa and ROR $\gamma t$ expression and activity are essential for full $\mathrm{T}_{\mathrm{H}} 17$ cell development, it is important to note that RORa and ROR $\gamma$ have roles outside of the immune system and are critical regulators of hepatic metabolism. Administration of SR1001 to C57BL/6 mice suppressed the expression of hepatic ROR target genes, Cyp7b1, Rev-erba, and Serpine 1 (Pai-1) suggesting that this class of compound may have metabolic effects; however, we noted no obvious toxicity in animals treated with SR1001 (Supplementary Fig. $9)^{16-18}$.

In summary, we describe a novel, first-in-class, highly selective drug targeting the orphan NRs RORa and ROR $\gamma$ that effectively suppresses $\mathrm{T}_{\mathrm{H}} 17$ cell differentiation and cytokine expression and reduces the severity of disease in an animal model of multiple sclerosis. Our data indicates that the targeting of $\mathrm{T}_{\mathrm{H}} 17$ cells, by blocking $\mathrm{RORa} / \gamma$ function with a synthetic ligand, is a tractable approach for potential therapeutic intervention. Current treatments for $\mathrm{T}_{\mathrm{H}}$ 17-mediated autoimmune diseases, including multiple sclerosis, utilize agents that are general immunosuppressant's and thus the side effect profile is significant. Clearly, our data demonstrates that by targeting RORa and ROR $\gamma$ one can specifically inhibit $\mathrm{T}_{\mathrm{H}} 17$ cells without affecting other $\mathrm{T}$ helper cell lineages thereby providing a more focused therapy that will not be a general immunosuppressant. Therefore, SR1001 and derivatives of this compound may represent a novel class of superior drugs to not only treat $\mathrm{T}_{\mathrm{H}} 17$-mediated autoimmune disorders, but ROR-mediated metabolic disorders as well.

\section{Methods Summary}

Synthesis of SR1001 (N-(5-(N-(4-(1,1,1,3,3,3-hexafluoro-2-hydroxypropan-2yl)phenyl)sulfamoyl)-4-methylthiazol-2-yl)acetamide). A solution of 2-(4aminophenyl)-1,1,1,3,3,3-hexafluoropropan-2-ol (0.88 g, 3.4 mmol), 2-acetamido-4- 
methylthiazole-5-sulfonyl chloride $(0.79 \mathrm{~g}, 3.1 \mathrm{mmol})$ in acetone $(15 \mathrm{~mL})$ and 2,6-lutidine $(0.73 \mathrm{~mL}, 6.2 \mathrm{mmol})$ was warmed to $60^{\circ} \mathrm{C}$ for $18 \mathrm{~h}$. The reaction was judged complete by analytical HPLC (starting materials consumed).

\section{Supplementary Material}

Refer to Web version on PubMed Central for supplementary material.

\section{Acknowledgements}

This work was supported by NIH grants to T.P.B (DK080201, DK089984 and MH092769) and P.R.G (GM084041) and a grant from the National Multiple Sclerosis Society grant to P.D.D. (RG389A2/1). Additionally, the efforts of P.R.G. and W.R.R. were supported by the NIH Molecular Library Screening Center Network (MLSCN) grant U54MH074404 (Hugh Rosen, Principal Investigator).

\section{References}

1. McGeachy MJ, Cua DJ. Th17 cell differentiation: The long and winding road. Immunity. 2008; 28:445-453. [PubMed: 18400187]

2. Bettelli E, Korn T, Oukka M, Kuchroo VK. Induction and effector functions of T(H)17 cells. Nature. 2008; 453:1051-1057. [PubMed: 18563156]

3. Littman DR, Rudensky AY. Th17 and Regulatory T Cells in Mediating and Restraining Inflammation. Cell. 140:845-858. [PubMed: 20303875]

4. Yang XXO, et al. T helper 17 lineage differentiation is programmed by orphan nuclear receptors ROR alpha and ROR gamma. Immunity. 2008; 28:29-39. [PubMed: 18164222]

5. Ivanov II, et al. The orphan nuclear receptor ROR gamma t directs the differentiation program of proinflammatory IL-17(+) T helper cells. Cell. 2006; 126:1121-1133. [PubMed: 16990136]

6. Ivanov II, Zhou L, Littman DR. Transcriptional regulation of Th17 cell differentiation. Semin. Immunol. 2007; 19:409-417. [PubMed: 18053739]

7. Manel N, Unutmaz D, Littman DR. The differentiation of human T-H-17 cells requires transforming growth factor-beta and induction of the nuclear receptor ROR gamma t. Nat. Immunol. 2008; 9:641-649. [PubMed: 18454151]

8. Kumar N, et al. The benzenesulfonamide T0901317 is a novel ROR \{alpha $\} /\{$ gamma $\}$ Inverse Agonist. Molecular Pharmacology. 2010; 77:228-236. [PubMed: 19887649]

9. Zhang FP, Meng GX, Strober W. Interactions among the transcription factors Runx1, ROR gamma t and Foxp3 regulate the differentiation of interleukin 17-producing T cells. Nat. Immunol. 2008; 9:1297-1306. [PubMed: 18849990]

10. Ichiyama K, et al. Foxp3 inhibits ROR gamma t-mediated IL-17A mRNA transcription through direct interaction with ROR gamma t. Journal of Biological Chemistry. 2008; 283:17003-17008. [PubMed: 18434325]

11. Wang Y, et al. Modulation of retinoic acid receptor-related orphan receptor alpha and gamma activity by 7-oxygenated sterol ligands. J Biol Chem. 285:5013-5025. [PubMed: 19965867]

12. Chopra AR, et al. Absence of the SRC-2 coactivator results in a glycogenopathy resembling Von Gierke's disease. Science. 2008; 322:1395-1399. [PubMed: 19039140]

13. Jin LH, et al. Structural Basis for Hydroxycholesterols as Natural Ligands of Orphan Nuclear Receptor ROR gamma. Molecular Endocrinology. 2010; 24:923-929. [PubMed: 20203100]

14. Xu J, Wagoner G, Douglas JC, Drew PD. Liver X receptor agonist regulation of Th17 lympocyte function in autoimmunity. J Leukoc Biol. 2009; 86:401-409. [PubMed: 19406833]

15. Xu JH, Racke MK, Drew PD. Peroxisome proliferator-activated receptor-alpha agonist fenofibrate regulates IL-12 family cytokine expression in the CNS: relevance to multiple sclerosis. Journal of Neurochemistry. 2007; 103:1801-1810. [PubMed: 17727629]

16. Delerive P, Chin WW, Suen CS. Identification of Reverb(alpha) as a novel ROR(alpha) target gene. J Biol Chem. 2002; 277:35013-35018. [PubMed: 12114512] 
17. Wada T, et al. Identification of oxysterol 7alpha-hydroxylase (Cyp7b1) as a novel retinoid-related orphan receptor alpha (RORalpha) (NR1F1) target gene and a functional cross-talk between RORalpha and liver X receptor (NR1H3). Mol Pharmacol. 2008; 73:891-899. [PubMed: 18055760]

18. Wang J, Yin L, Lazar MA. The orphan nuclear receptor Rev-erb alpha regulates circadian expression of plasminogen activator inhibitor type 1. J Biol Chem. 2006; 281:33842-33848. [PubMed: 16968709] 
a

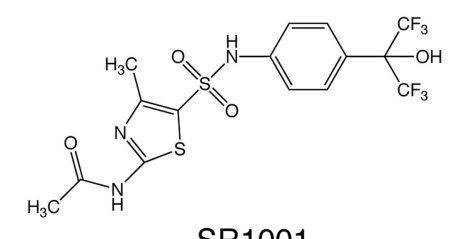

SR1001

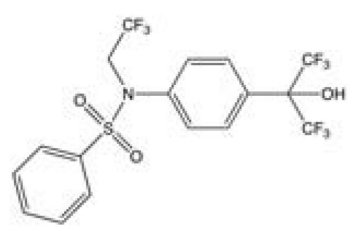

$\mathrm{T} 1317$

C
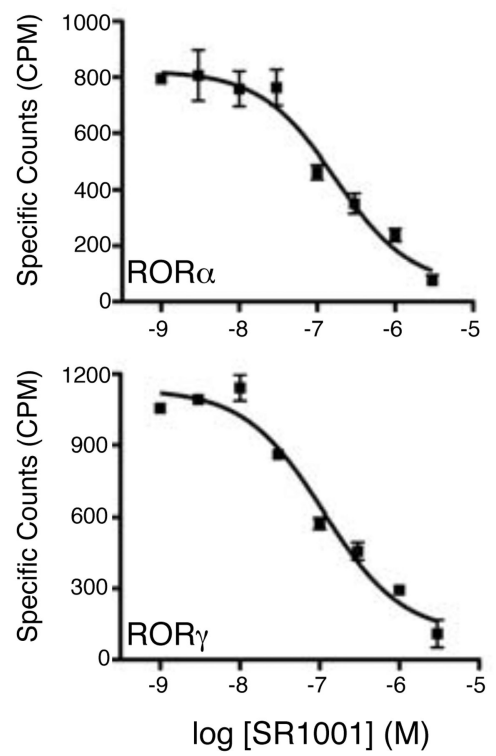

b
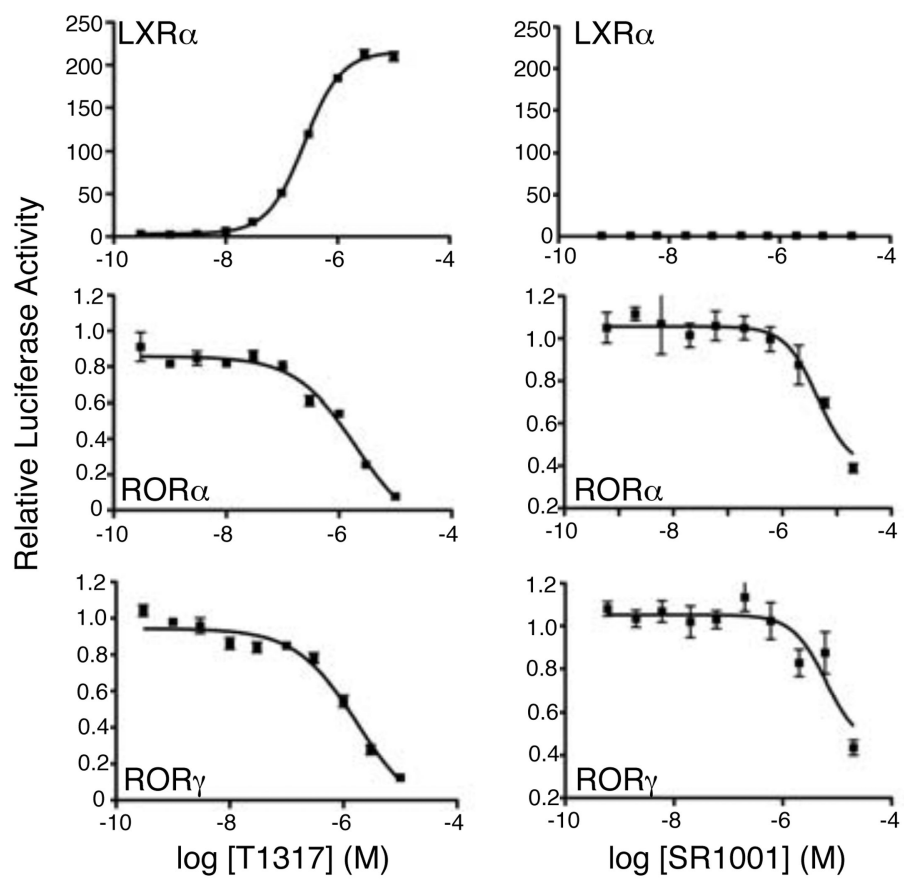

d
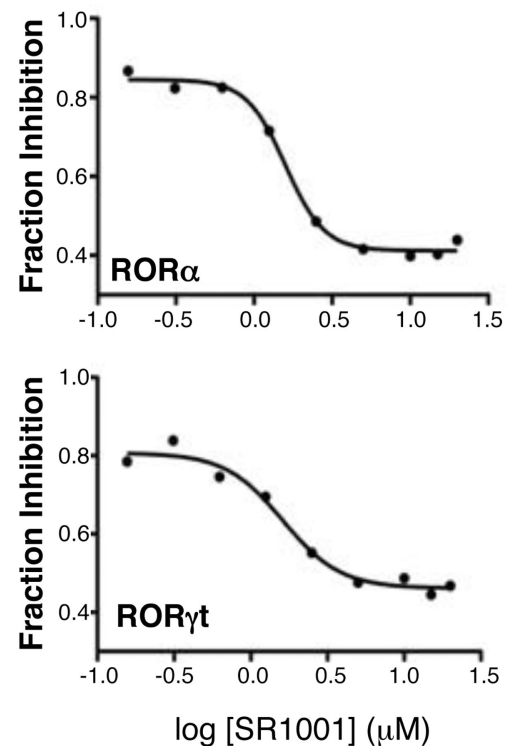

e

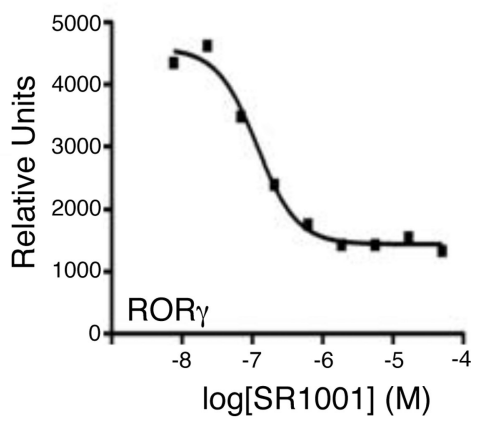

Figure 1. SR1001 is a selective RORa and ROR $\gamma$ inverse agonist a, Structure of SR1001 and T0901317 (T1317). b, GAL4-LXRa, GAL4-RORa, and GAL4ROR $\gamma$ cotransfection assays in HEK293 cells comparing T1317 to SR1001 $(n=8)$. c, Competition radioligand binding assays illustrating the direct binding of SR1001 to the LBD of RORa and ROR $\gamma$ relative to $\left[{ }^{3} \mathrm{H}\right] 25$-hydroxycholesterol $(n=4)$. d, SR1001 dosedependently inhibits an $I l 17$ promoter-driven luciferase construct in the presence of RORa or ROR $\gamma$ t in HEK293 cells. Results are normalized to vehicle (DMSO) control $(n=4)$. e, 
AlphaScreen assay indicating SR1001 dose-dependently inhibits the recruitment of a TRAP220 NR box 2 peptide to the LBD of ROR $\gamma(n=3)$. Error bars denote sem. 
a
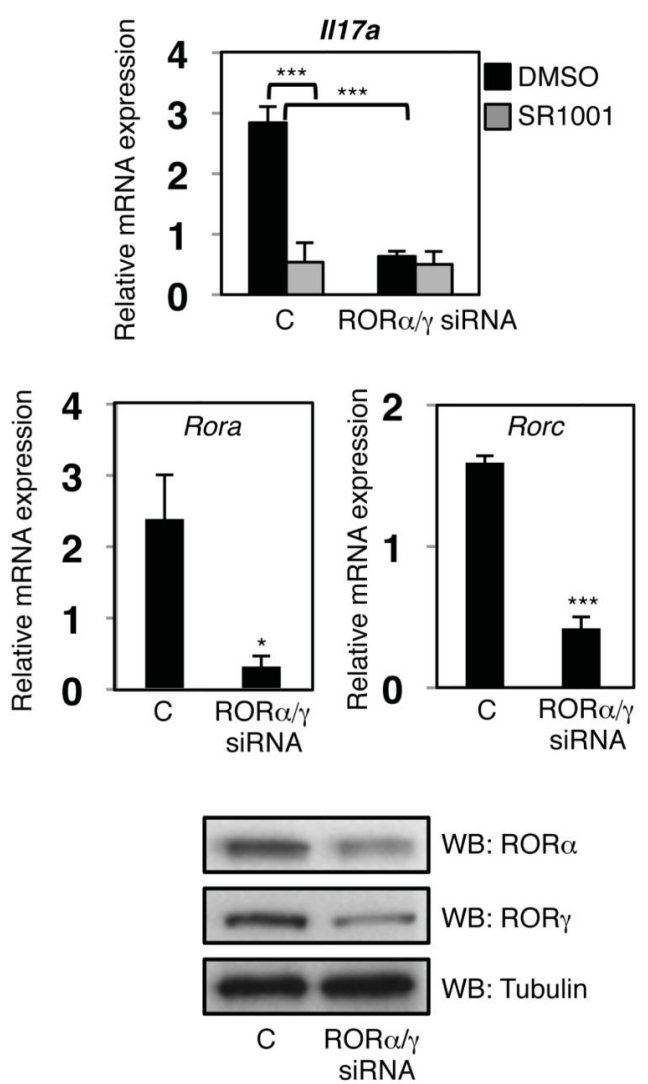

d

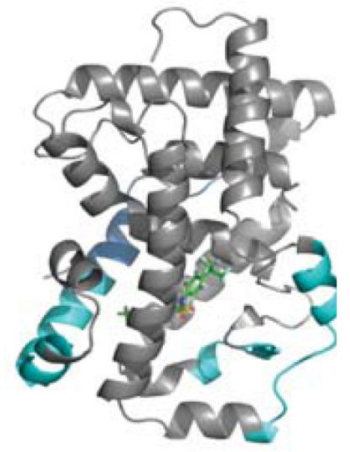

SR1001

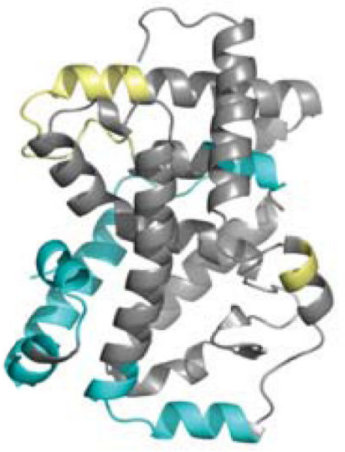

SRC2
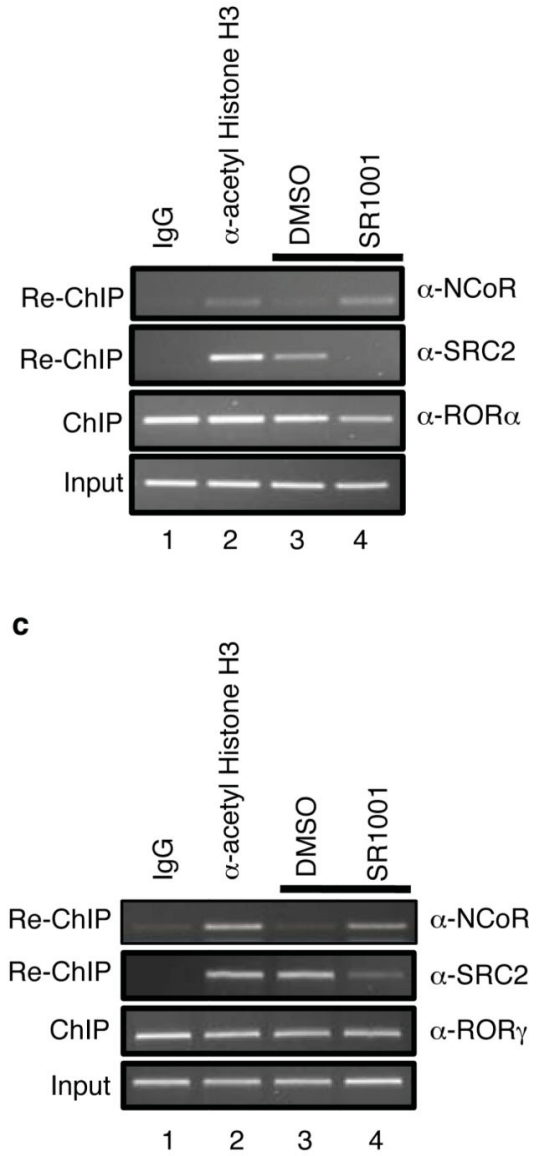

Figure 2. SR1001 modulates the expression of ROR target genes by decreasing coactivator recruitment

a, Il17a, Rora, and Rorc mRNA expression in EL4 cells treated with control (C), or mouse RORa/ $\gamma$ siRNA, vehicle (DMSO), or SR1001 (10 $\mu \mathrm{M}, 24$ hours) $(n=3)$. Protein expression of RORa and ROR $\gamma$ is shown. $* P<0.05$; $* * *<0.005$. b, ChIP-reCHIP assay in EL4 cells illustrating that SR1001 reduces b, RORa- and $\mathbf{c}$, ROR $\gamma$-dependent recruitment of SRC-2 and promotes recruitment of NCoR to the $I l 17$ promoter. d, Illustration of the HDX kinetics 
of peptic peptides derived from the ROR $\gamma$ LBD.. Cyan indicates an increase in protection to exchange; yellow represents a decrease in protection to exchange. Error bars denote sem. 

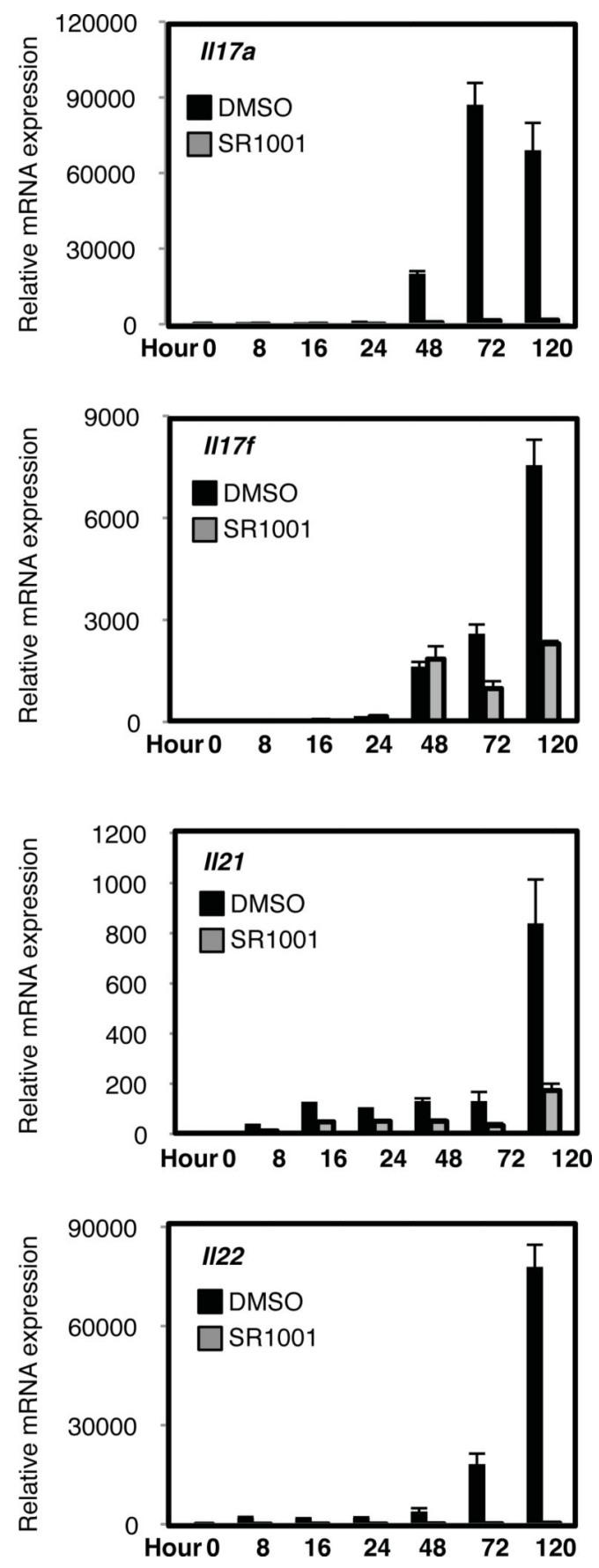

Figure 3. SR1001 inhibits the expression of cytokines expressed by $\mathbf{T}_{\mathbf{H}} 17$ cells

$I l 17 a, I l 17 f, I l 21$, and $I l 22$ mRNA expression in splenocytes differentiated under $\mathrm{T}_{\mathrm{H}} 17$

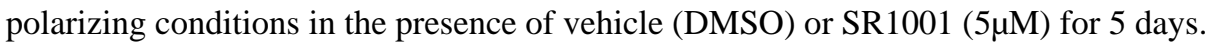
mRNA expression levels are normalized to Gapdh $(n=3)$. Error bars denote sem. 
a
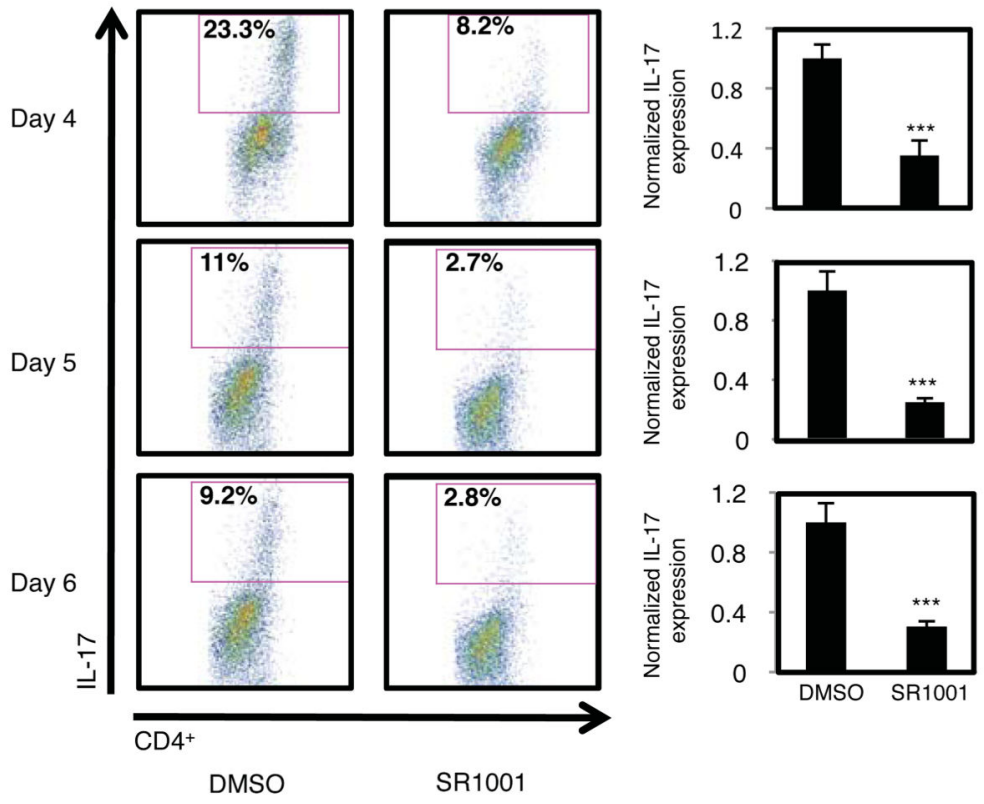

b

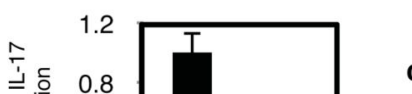

e
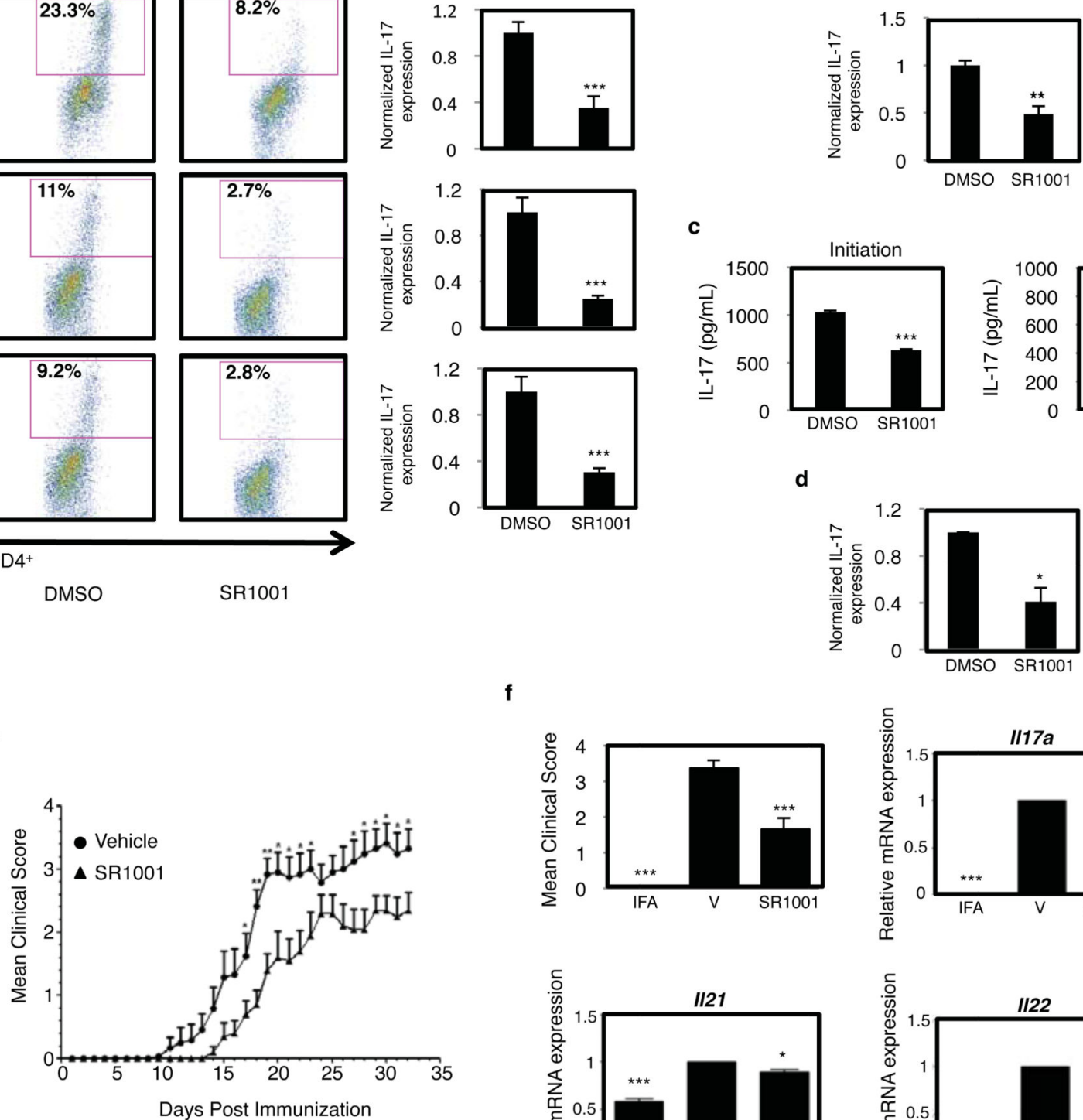

C

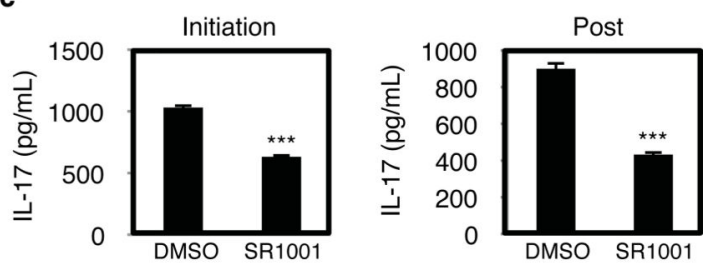

d
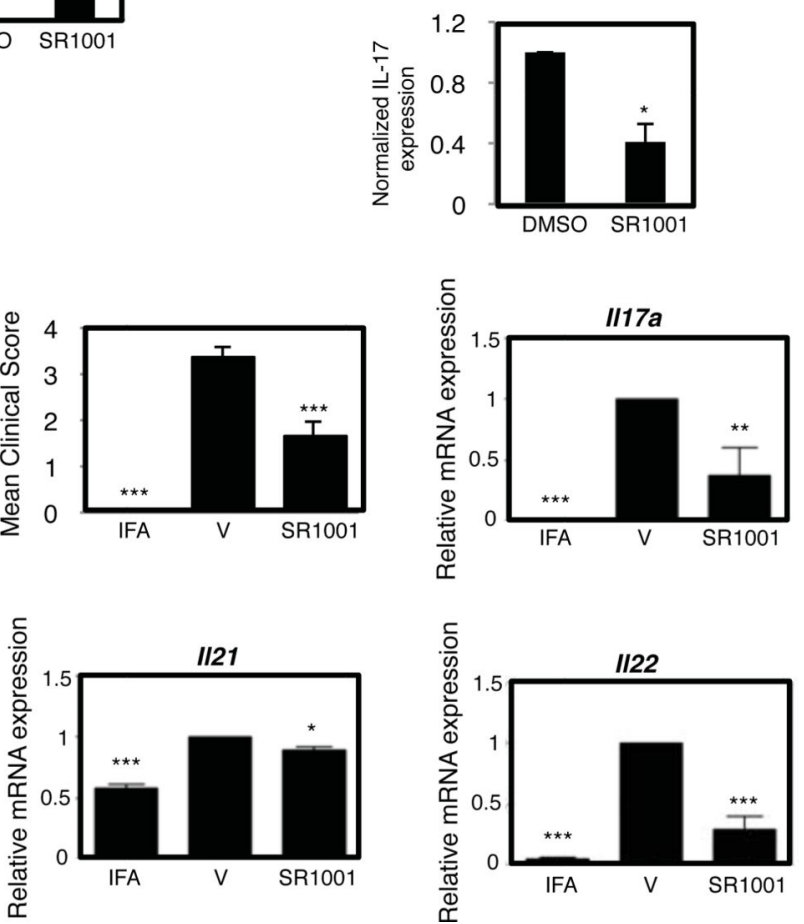

Figure 4. SR1001 inhibits $\mathbf{T}_{\mathbf{H}} \mathbf{1 7}$ cell development and IL-17A secretion

a, IL-17 expression in splenocytes cultured under $\mathrm{T}_{\mathrm{H}} 17$ polarizing conditions with vehicle control (DMSO) or SR1001 (5 $\mu \mathrm{M})$. Graphs represent the average percentage of IL-17A expressing cells normalized to vehicle control $(n=3)$. $\mathbf{b}$, IL-17 expression in differentiated purified naïve murine $\mathrm{CD}^{+} \mathrm{T}$ cells normalized to vehicle control $(n=3)$. c, IL-17A secretion from splenocytes cultured under $\mathrm{T}_{\mathrm{H}} 17$ polarizing conditions with SR1001 $(5 \mu \mathrm{M})$ for 3 days $(n=3)$. d, Intracellular IL-17A expression in hPBMCs cultured for 24 hours with vehicle or SR1001 $(5 \mu \mathrm{M})(n=3)$. e, Treatment with SR1001 suppresses the clinical severity of EAE: vehicle $(\mathbf{O}, n=12)$ or SR1001 $\left(25 \mathrm{mg} \mathrm{kg}^{-1}\right)(\mathbf{\Lambda}, n=10)$. f, $I l 17 a, I l 21$, and $I l 22 \mathrm{mRNA}$ 
expression from spinal cords of sham-operated (IFA), vehicle control (V), or drug treated (SR1001) mice. $(n=4)$. Error bars denote sem. ${ }^{* * *} P<0.001 ; * * P<0.01$; and $* P<0.05$. 